\title{
'Desain Interior Galeri Rumah Batik dengan Konsep Jawa Timur Kontemporer sebagai Sarana Workshop dan Edukasi
}

\author{
Robbi Azis Irawan dan Anggri Indraprasti \\ Jurusan Desain Interior, Fakultas Teknik Sipil dan Perencanaan, Institut Teknologi Sepuluh Nopember \\ (ITS) \\ Jl. Arief Rahman Hakim, Surabaya 60111 Indonesia \\ e-mail: anggri@prodes.its.ac.id
}

\begin{abstract}
Abstrak-Bertujuan untuk mengembangkan dan melestarikan batik di Jawa Timur, Faiqah Ismail seorang pengrajin batik asal Pamekasan Madura, yang juga mempunyai perusahaan di bidang produksi batik bernama PT Fiesta Madura. Berinisiatif membangun sebuah rumah khusus batik di kota Surabaya yang dinamai dengan Rumah Batik Jawa Timur, dibuka untuk umum tahun 2004. Rumah Batik Jawa Timur menyediakan fasilitas berupa workshop room, sebagai sarana belajar untuk mempraktekkan cara membuat kain batik mulai dari proses menggambar motif diatas kain, hingga proses menjadi kain batik yang siap pakai. Kegiatan workshop tersebut diikuti oleh kalangan pelajar dari sekolah yang mengikuti secara berkelompok, maupun perseorangan, dari remaja maupun dewasa, selain tempat workshop, di Rumah Batik Jawa Timur juga terdapat mini galeri yang mempunyai koleksi batik langka dari 16 kabupaten di Jawa Timur, serta sebuah store yang menjual kain dan pakaian batik untuk pria dan wanita. Perancangan desain interior pada obyek tugas akhir ini menerapkan konsep yang mengusung ciri khas budaya Jawa Timur, diantaranya adalah pada penggunaan ukiran yang berasal dari peninggalan Majapahit, ukiran Madura, bentuk furniture yang berasal dari transformasi batik kawung, serta material batu bata yang terinspirasi dari material ciri khas candi yang ada di Jawa Timur.

Penggunaan elemen - elemen interior tersebut digunakan untuk menghadirkan suasana kesan etnik khas Jawa Timur didalam keseluruhan ruangan, serta sebagai ikon identitas dari Rumah Batik Jawa Timur. Seiring perkembangan jaman yang serba mengikuti trend pada masyarakat perkotaan, salah satunya kota Surabaya, maka gaya interior kontemporer juga dipadukan dalam konsep perancangan ini. Penggabungan konsep kontemporer dengan langgam Jawa Timur digunakan dengan tujuan sebagai penarik minat masyarakat yang menuntut kebutuhan akan ruangan yang nyaman, serta mewakili gaya hidup masa kini yang cenderung menginginkan sesuatu yang unik dan menarik, baik bagi kalangan dewasa maupun anak muda. Dengan tujuan agar meningkatkan antusias ketika mengikuti kegiatan workshop di dalam Rumah Batik Jawa Timur dan segala hal yang berhubungan dengan batik, sebagai warisan budaya Indonesia yang mempunyai nilai seni tinggi.
\end{abstract}

Kata Kunci-Batik, Edukasi, Galeri, Jawa Timur, Rumah, Store, Workshop.

\section{PENDAHULUAN}

$\mathrm{B}$ ATIK adalah warisan budaya yang mempunyai nilai seni tinggi yang merupakan salah satu cara pembuatan pakaian yang dikenal khususnya di pulau Jawa, namun saat ini berbagai macam desain motif batik telah banyak muncul di berbagai daerah di Indonesia. Perkembangan batik Nusantara cukup tinggi, setelah ditetapkan oleh UNESCO sebagai warisan kemanusiaan untuk budaya lisan dan non bendawi sejak 2 oktober 2009, banyak masyarakat yang menjual berbagai produk ataupun pakaian berasal dari motif batik salah satunya adalah masyarakat Madura [1].

PT Fiesta Madura adalah salah satu perusahaan produsen kerajinan pembuatan batik dengan motif dan warna khas Madura yang berlokasi di Jalan Proppo no.71 Pamekasan, selain sebagai produsen yang menjual batik di wilayah Madura, PT Fiesta Madura juga mempunyai butik yang berlokasi di Royal Plaza Surabaya dan sebuah Rumah Batik yang menjadi tempat galeri dan workshop, Keberadaan Rumah Batik Jawa Timur ini merupakan prakarsa dari pemilik PT. Fiesta Madura, Ibu $\mathrm{Hj}$. Faiqah Ismail yang memang adalah seorang pengrajin dan pengkoleksi batik dari berbagai daerah di Jawa Timur yang kemudian diturunkan kepengusahaannya kepada putranya yang bernama bapak Syarif Usman.

Ibu $\mathrm{Hj}$. Faiqah Ismail kemudian memutuskan untuk membangun rumah batik yang berlokasi di Jalan Tambak Dukuh 1 no.4 Surabaya, namun sekarang telah berpindah lokasi ke Jalan Margorejo no.143 Surabaya yang berfungsi sebagai workshop dan store, karena antusias masyarakat yang baik khususnya kalangan pelajar yang ingin belajar mengenai sejarah dan segala hal yang berhubungan dengan batik, hal inilah yang menjadi dasar untuk menghadirkan galeri Rumah Batik Jawa Timur yang mempunyai tujuan dengan mendirikan galeri sebagai tempat pameran dan penjualan, serta memberikan fasilitas workshop untuk mengedukasi masyarakat Surabaya dan masyarakat daerah lain di Jawa Timur, agar dapat mempelajari proses pembuatan batik dan mengapresiasi filosofi motif batik khas Jawa Timur sebagai warisan budaya.

\section{A. Permasalahan}

1. Bagaimana merancang desain interior dengan penggabungan gaya Kontemporer dan langgam Jawa Timur 
dengan tetap memenuhi kenyamanan aktivitas para pengguna.

2. Bagaimana mengatur dan menyediakan fasilitas yang nyaman dalam rancangan desain yang mampu memenuhi kebutuhan pengguna.

3. Bagaimana mempelajari proses pembuatan dan bahan kain batik sehingga dapat dipakai sebagai acuan dalam mendesain ruang yg bersangkutan.

4. Bagaimana merancang bentukan desain sesuai konsep Kontemporer dan langgam Jawa Timur yang dapat memunculkan suasana dan karakteristik ruang yang khas sehingga diingat oleh pengunjung.

\section{B. Ruang Lingkup}

1. Ruangan yang didesain meliputi Galeri Batik, Ruang Workshop, dan Ruang Seminar

2. Penambahan beberapa kebutuhan ruang untuk fungsi pendukung Galeri Batik.

3. Mengupayakan sebuah layout yang baik agar membentuk sebuah sirkulasi yang baik pula dalam perancangan Galeri Batik.

\section{Tujuan}

1. Mampu menciptakan desain interior ruangan sesuai konsep perancangan dan tidak menjadi masalah bagi aktivitas pengunjung.

2. Mampu menghadirkan ciri khas desain interior kontemporer dan suasana langgam Jawa Timur kedalam interior ruangan.

3. Mampu memenuhi kebutuhan fasilitas yang layak dan aman dalam hal pameran dan fungsi konservasi kain batik yg langka.

4. Mampu memenuhi standart kenyamanan dan keamanan bagi pengguna dalam menjalankan aktivitas didalam interior ruangan.

\section{Manfaat}

1. Menemukan berbagai masalah dan memecahkan sebuah masalah baru yang timbul akibat adanya permintaan dan konsep yang baru.

2. Menambah wawasan akan desain interior tentang tata cara mendesain ruangan galeri dan workshop.

3. Memberikan referensi - referensi baru dan masalah masalah baru yang diperoleh melalui studi objek pembanding pada proses analisis eksisting.

4. Memberikan edukasi terhadap masyarakat dan anak-anak akan pentingnya praktek dalam workshop serta pengetahuan akan seni budaya batik dan Jawa Timur.

\section{URAIAN PENELITIAN}

\section{A. Teknik Pengumpulan Data}

Pada desain interior Rumah Batik Jawa Timur ini dilakukan tahap pengumpulan data melalui beberapa metode pengumpulan data, yaitu pengumpulan data secara langsung dan tidak langsung. Pengumpulan data secara langsung dapat dilakukan dengan cara observasi ke objek desain yang dituju, wawancara kepada kepala owner dan pengunjung. Sedangkan pengumpulan data secara tidak langsung yaitu dilakukan dengan mengumpulkan data dari berbagai literatur seperti buku, jurnal ilmiah, dan internet.

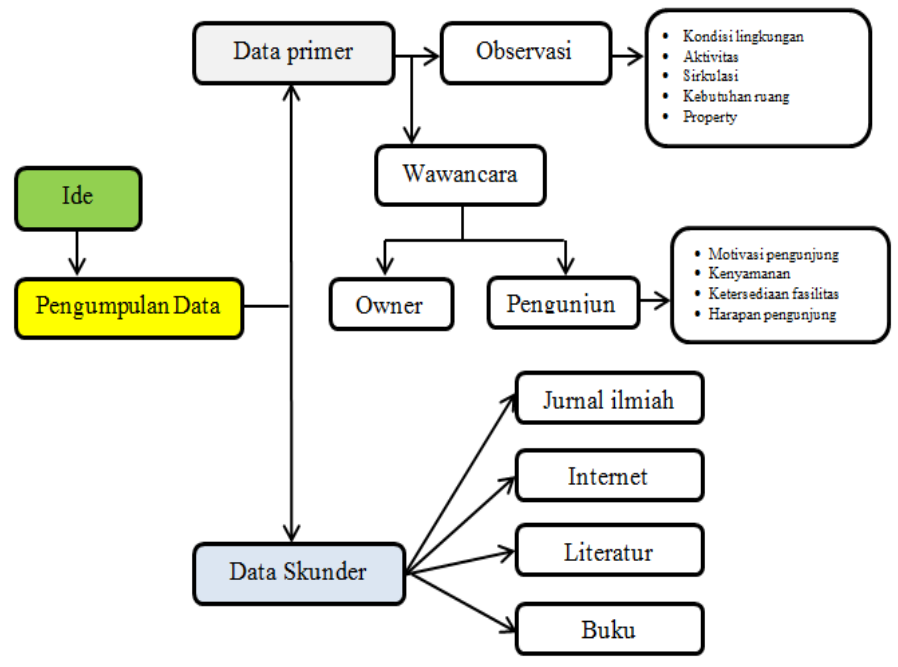

Bagan 1. Metode pengambilan data

1. Observasi Lapangan (Langsung).

Metode observasi dilakukan dengan mengunjungi langsung lokasi dari Rumah Batik Jawa Timur. Dengan observasi, penulis dapat merasakan aktifitas dari pengguna serta kebutuhannya dan bisa menilai konsep apa yang paling cocok untuk diterapkan di Rumah Batik Jawa Timur. Data yang diperoleh antara lain:

a. Mengetahui aktifitas pengguna Rumah Batik Jawa Timur.

b. Mengetahui keadaan eksisting elemen-elemen pembentuk desain.

- Konsep interior ruangan yang belum dipikirkan dengan baik sehingga suasana ruangan terkesan tidak teratur.

- Mengetahui beberapa furnitur yang digunakan di fasilitas workshop dan galeri masih belum sesuai dengan kebutuhannya.

c. Mengetahui kondisi lingkungan sekitar Rumah Batik Jawa Timur. d. Pengaturan layout di Rumah Batik Jawa Timur.

- Penataan layout furniture yang belum diatur dengan baik sehingga berpotensi menganggu aktifitas pengunjung.

- Belum lengkapnya fasilitas pendukung kegiatan workshop terutama dalam hal proses pewarnaan kain batik.

\section{Interview (Wawancara)}

Metode wawancara dilakukan owner Rumah Batik Jawa Timur demi mengetahui secara lebih detail tentang tantangan yang dirasakan dan harapan kedepan dari sudut pandang pecinta dan pengusaha batik. Data yang diperoleh antara lain:

a. Visi dan Misi Rumah Batik Jawa Timur.

$b$. Fasilitas yang tersedia untuk ruang galeri dan praktek untuk ruang workshop.

c. Perawatan terhadap kain batik pada display pameran dan properti untuk membatik peserta workshop.

d. Permasalahan desain interior yang ada di Rumah Batik Jawa Timur. 


\section{Studi Literatur}

Untuk menunjang terciptanya sebuah desain yang ideal pada Rumah Batik Jawa Timur maka penulis mencari data-data literatur yang berkaitan dengan perpustakaan serta konsep yang diambil dari berbagai buku-buku dan media lainnya. Data dan informasi yang dicari yaitu:

a. Kajian tentang galeri, berkaitan dengan definisi galeri, fasilitas ruang pameran dan persyaratan pada ruang galeri.

b. Kajian tentang data antropometri pada aktifitas pengunjung

c. Kajian tentang karakteristik langgam yang akan digunakan.

d. Kajian tentang warna dan pencahayaan.

\section{B. Tahapan Desain}

Metode desain interior pada Rumah Batik Jawa Timur setelah mendapat dan mengumpulkan data-data hasil riset desain dapat dilakukan melalui tahapan-tahapan dalam mendesain, yaitu:

1. Penyusunan konsep desain

Menuliskan semua hasil riset desain yang digunakan sebagai solusi bagi permasalahan-permasalahan yang muncul dan telah terselesaikan lalu diangkat berdasakan hasil dari studi pustaka.

2. Desain awal

Ide-ide desain dan penyelesaian awal dari permasalahan yang didapatkan pada saat analisis data-data yang didapatkan.

\section{Alternatif desain}

Pada tahap ini desain tersebut dibuat lebih dari satu, sehingga memperoleh alternatif desain. Alternatif desain disesuaikan dengan konsep desain dan dapat kembali pada proses konsep desain jika pada alternatif ditemukan ide-ide baru.

4. Evaluasi

Pada tahap ini, keseluruhan alternatif desain akan dipilih melalui tahap kriteria dan score (weight method) hingga diperoleh satu desain terbaik. Kriteria yang diajukan yaitu dari segi sirkulasi, zoning ruang per area sesuai fungsinya, tata layout per area, dst.

5. Pengembangan desain

Setelah tahap evaluasi selesai, maka desain tersebut akan melalui proses pengembangan desain, jika pada tahap ini desain kurang sesuai maka dapat kembali lagi pada proses alternatif desain.

6. Desain akhir

Jika keseluruhan tahap desain selesai dilaksanakan, maka sampailah padatahap desain akhir berupa sketsa 3d, gambar teknik, maket dan animasi.

\section{KONSEP DESAIN}

\section{A. Konsep Makro}

Konsep makro diambil dari konsep utama desain yaitu kontemporer, inti utama dari konsep desain ini adalah perancangan ruangan yang serba mengikuti perkembangan jaman ketika desain ini diterapkan dalam suatu ruang [2]. Penggunaan gaya kontemporer walaupun terkesan terlalu bebas karena bisa dipadukan dengan gaya interior yang lain, namun ciri khas utama pada konsep desain masih bisa dikenali dengan beberapa ciri khas yang juga sesuai dengan perencanaan galeri Rumah Batik Jawa Timur dengan berbagai segmentasi pengunjung dari kalangan anak anak hingga orang dewasa.

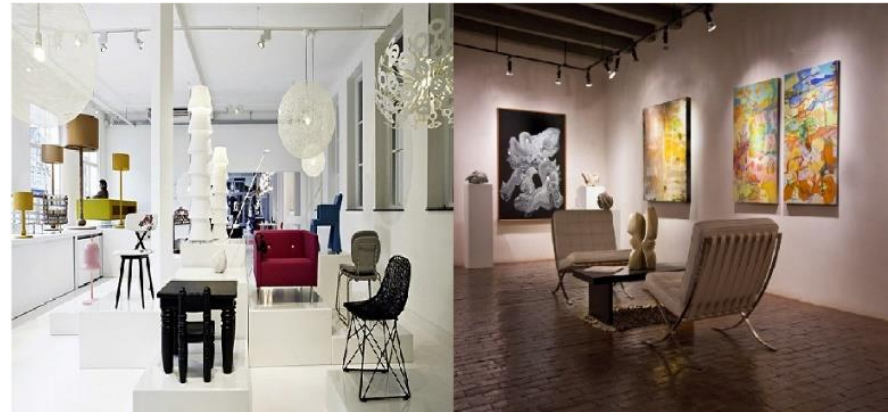

Gambar 1. Konsep interior makro

\section{B. Konsep Mikro}

Konsep mikro dari perancangan ini dibagi menjadi 4 bagian konsep mikro, yaitu konsep mikro dinding, lantai, plafon, dan furnitur [3]. Berikut pembahasan dari ke-4 konsep mikro tersebut :

\section{Konsep Dinding}

Penggunaan batu pualam pada ruang workshop, selain menimbulkan kesan mewah dan dingin, dinding batu pualam juga cocok digunakan karena ruangan yang rentan dengan asap dan air. Akibat aktifitas membatik hingga ke proses perendaman untuk pewarnaan, karena material tersebut mudah dibersihkan dan lebih cepat kering karena teksturnya yang kasar dan menyerap air sehingga ruangan berkurang kelembabannya dan dapat terhindar dari kemungkinan munculnya jamur dan lumut.

Pada area galeri terdapat penggunaan material batu bata yang juga mewakili konsep Jawa timur, terinspirasi dari material yang berasal pada bangunan candi yang terdapat di beberapa daerah di provinsi Jawa Timur. Penggunaan material batu alam juga termasuk salah satu ciri khas desain interior kontemporer.

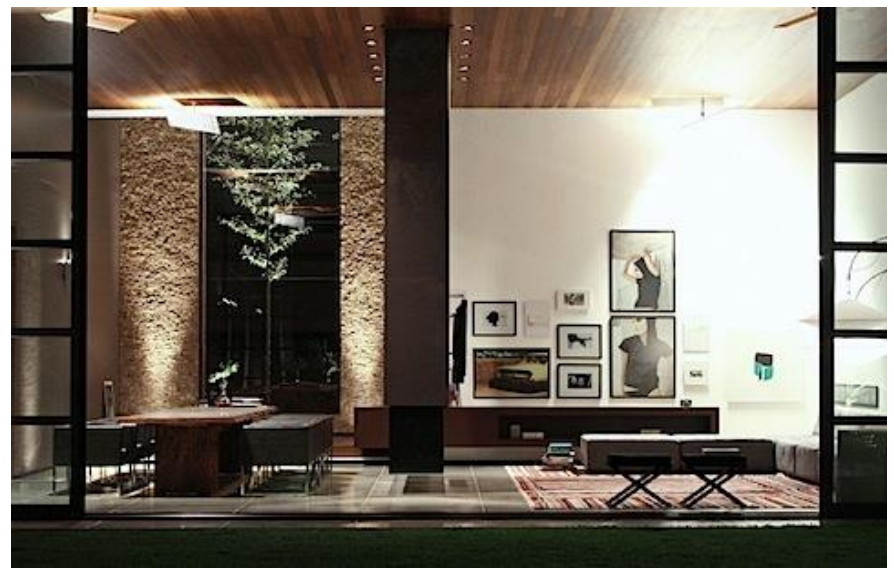

Gambar 2. Konsep dinding

\section{Konsep Lantai}

Konsep lantai yang digunakan pada ruang galeri dan workshop adalah pengaplikasian border lantai, pengertian border lantai sendiri adalah penggabungan beberapa macam jenis lantai. Perbedaan bisa timbul dari warna, motif maupun tekstur atau bahan yang digunakan, pada area galeri misalnya yaitu menggunakan 3 macam jenis lantai yaitu lantai granit, lantai keramik dan kayu parket, ketiga jenis lantai ini memiliki 
porsi yang tidak sama dan harus mempunyai 1 jenis lantai yang digunakan sebagai material utama.

Lantai keramik dan kayu parket pada galeri digunakan untuk memunculkan kesan etnik khas Jawa Timur namun tetap tidak terkesan kuno, sementara lantai utamanya menggunakan material granit rough warna hijau yang menonjolkan konsep kontemporer pada ruangan tersebut. Pengaplikasian border lantai juga diterapkan pada ruang workshop yaitu dengan menggunakan material lantai granit polished, lantai concrete dan kayu parket.

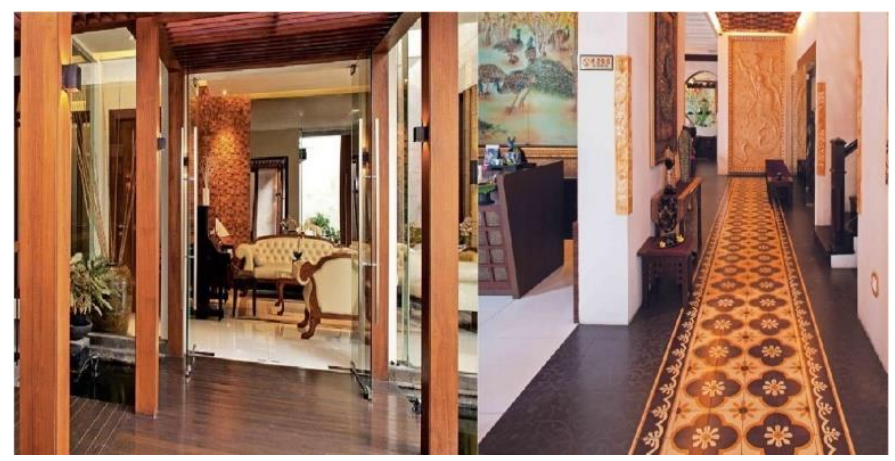

Gambar 3. Konsep lantai

\section{Konsep Plafon}

Penerapan plafon pada konsep desain kontemporer cenderung memliki ciri khas yang flat serta membiarkan terkesan luas dan lega, dengan penambahan aksen lampu gantung agar tidak terkesan monotone. Seperti pada ruang galeri, levelling turun pada plafon tidak ada sama sekali namun hanya menambahkan beberapa spotlight dan lampu gantung khas Jawa. Selain sebagai lighting ruangan penggunaan lampu gantung etnik tersebut juga mewakili langgam Jawa timur dalam perancangan, minimnya permainan desain pada plafon juga sangat tepat dilakukan sebagai penyeimbang. Karena bagian furniture yang memiliki ukiran serta kain batik dengan berbagai motifnya sendiri sudah menciptakan kesan yang penuh terhadap pandangan mata penggunanya.

Penggunaan plafon balok kayu yang dominan dengan elemen garis digunakan pada area workshop, karena kondisi aktifitas membatik yang memunculkan asap. Oleh karena kayu sebagai material cover dari plafon gypsum agar asap yang mengarah keatas tidak langsung mengenai lapisan plafon utama, selain

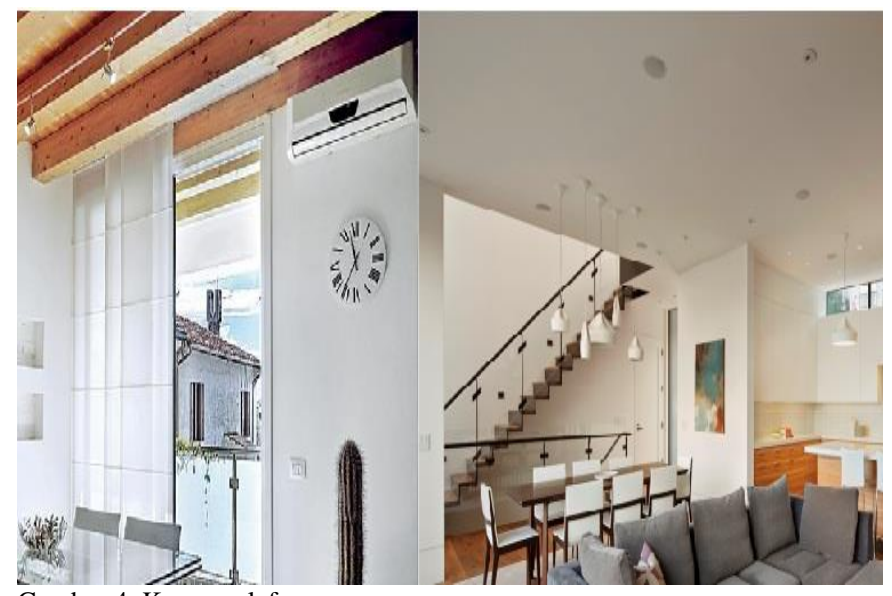

Gambar 4. Konsep plafon mudah dibersihkan, kayu dapat dilapisi dengan cat waterproofing.

4. Konsep Furniture

Konsep furniture didesain dengan bentuk dasar geometri tetap dengan adanya detail ukiran dan lekukan, karena gaya kontemporer berbeda dengan konsep desain modern yang selalu wajib menerapkan elemen geometris, beberapa furnitur tambahan juga memiliki ciri khas desain vintage etnik khas Jawa sebagai perpaduan desain dengan gaya kontemporer.

Berbeda dengan desain display Rumah Batik Jawa Timur yang sebelumnya yang sangat kental dengan nuansa Madura, pada desain furnitur dalam perancangan ini ukiran khas Jawa Timur yaitu ukiran majapahit dan madura tetap dimunculkan namun dengan penggantian warna yang semula berwarna cenderung ke pop art diubah ke color palette pastel seperti warna putih, krem dan abu abu. Tujuannya adalah agar nampak adanya satu kesatuan dengan gaya desain kontemporer dan menghindari kesan terlalu bertabrakan dengan motif kain batik yang di display.

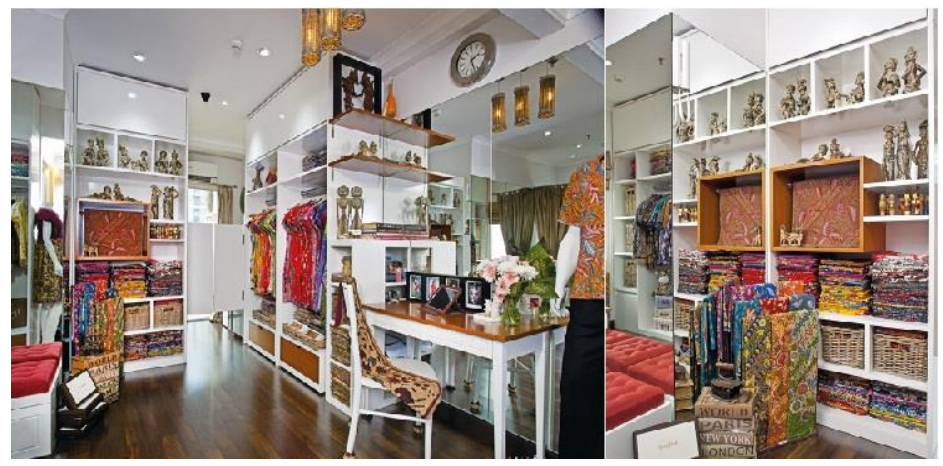

Gambar 5. Konsep furniture

\section{Konsep Elemen Estetis}

Bentukan elemen estetis menggunakan analogi bentukan gunungan dengan ukiran Majapahit, dengan maksud menciptakan bentuk gunungan yang baru dan lebih mengikuti trend. Display baju gantung juga dibuat lebih simpel dengan aksen ukiran agar terlihat penggabungan konsep Jawa Timur dan kontemporer.
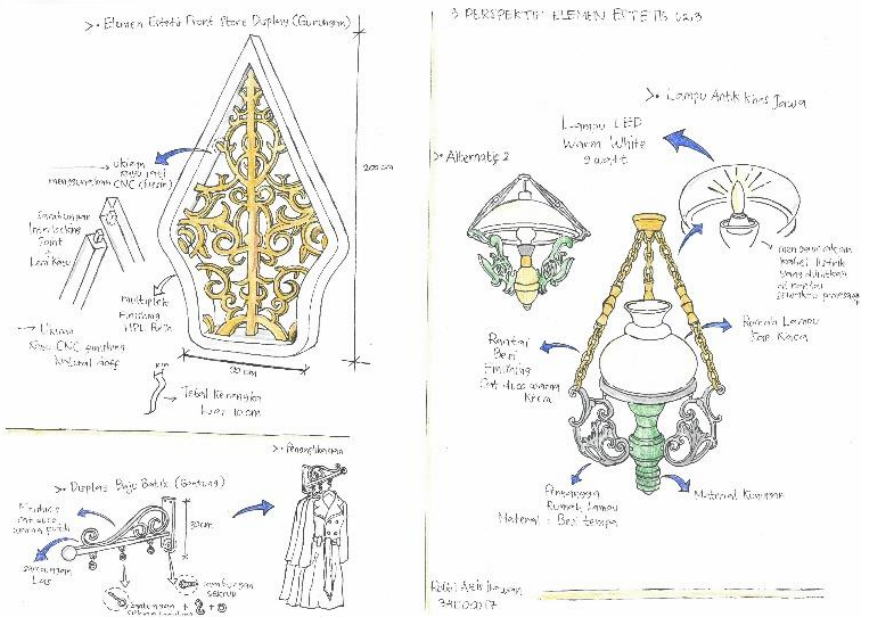

Gambar 6. Konsep elemen estetis 


\section{DESAIN AKHIR}

\section{A. Ruang Terpilih-Galeri Batik}

Pada gambar dibawah ini merupakan hasil akhir dari proses desain dan menghasilkan gambar perspektif dari suasana galeri Rumah Batik Jawa Timur, nampak sekali perpaduan seimbang antara gaya kontemporer yang tervisualisasi lewat bagian lantai dan plafon yang dibuat simpel serta terlihat luas, lalu dengan bentukan display kaca kain batik yang merupakan perpaduan unsur kontemporer dan Jawa Timur, ukiran Madura, Majapahit, motif kawung dan display berbentuk soko guru semakin menambah kesan etnik dari konsep langgam Jawa Timur.

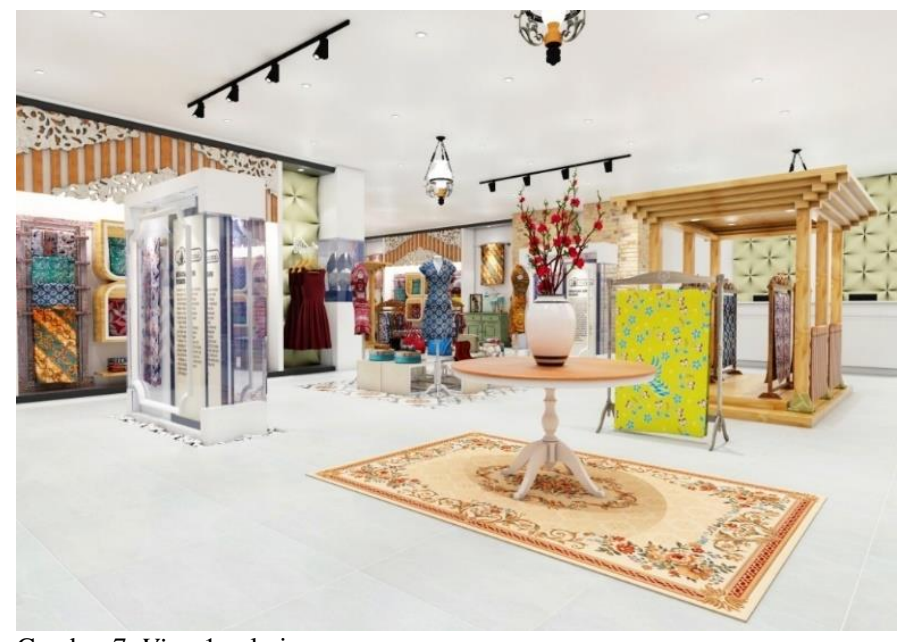

Gambar 7. View 1 galeri

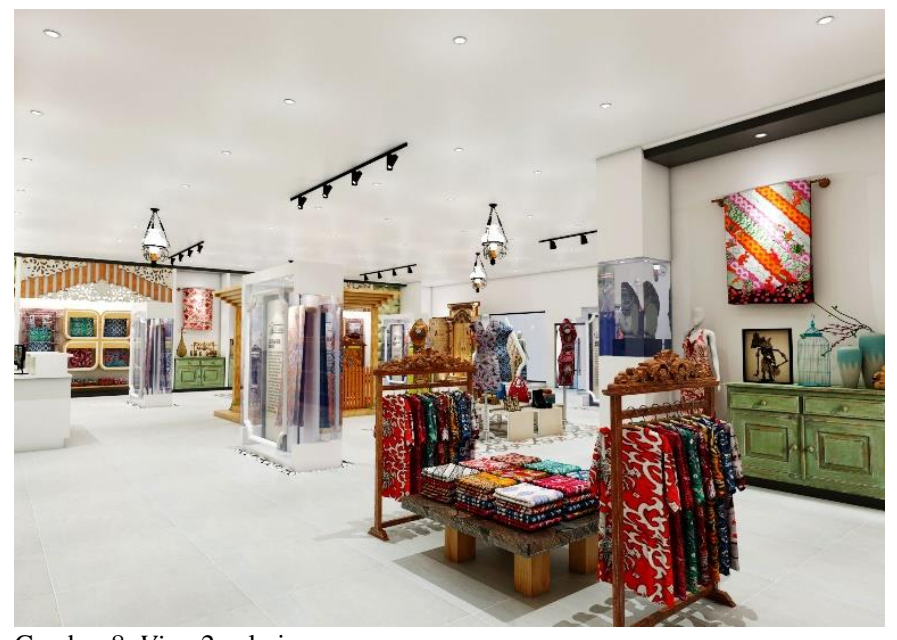

Gambar 8. View 2 galeri

\section{B. Ruang Terpilih—Ruang Workshop}

Berbeda dengan ruang galeri yang kuat sekali dengan unsur khas Jawa Timur, pada visualisasi suasana ruang workshop lebih dominan dalam unsur gaya interior kontemporernya. Ditandai dengan banyak sekali elemen garis pada keseluruhan interiornya, mulai dari bagian dinding kaca, plafon kayu dengan list kayu bergaris dan pembagian level lantai yang lurus memanjang, tetapi porsi dari elemen interior Jawa Timur tidak sepenuhnya hilang, yaitu masih terlihat pada penggunaan elemen kayu parket pada lantai lesehan membatik serta pada furniture dingklik. Meja bermaterialkan rotan, gawangan, serta elemen estetis pada penutup kusen pintu yang bermotif batik kawung dan diatasnya juga terdapat pajangan kepala barongan khas Jawa Timur.

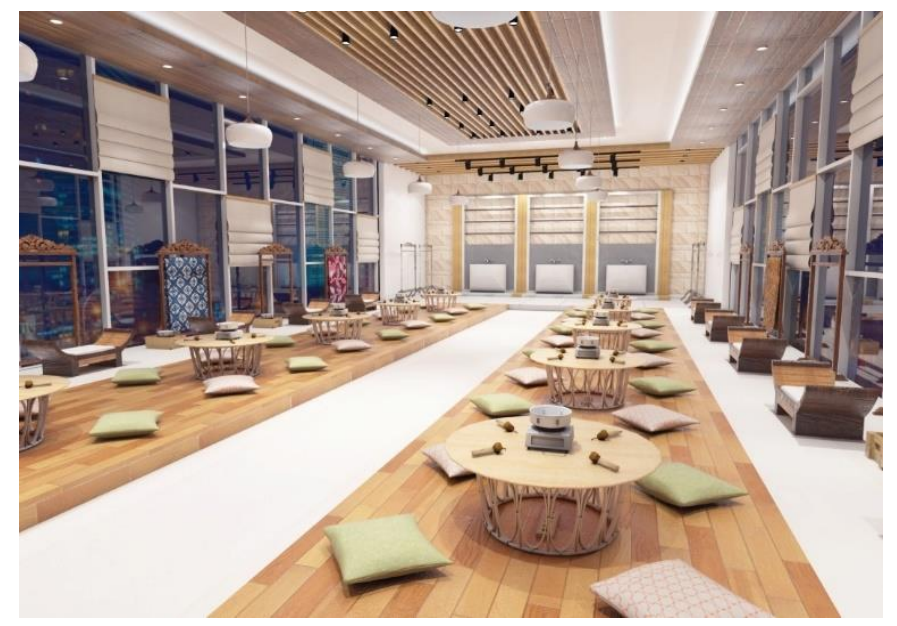

Gambar 9. View 1 ruang workshop

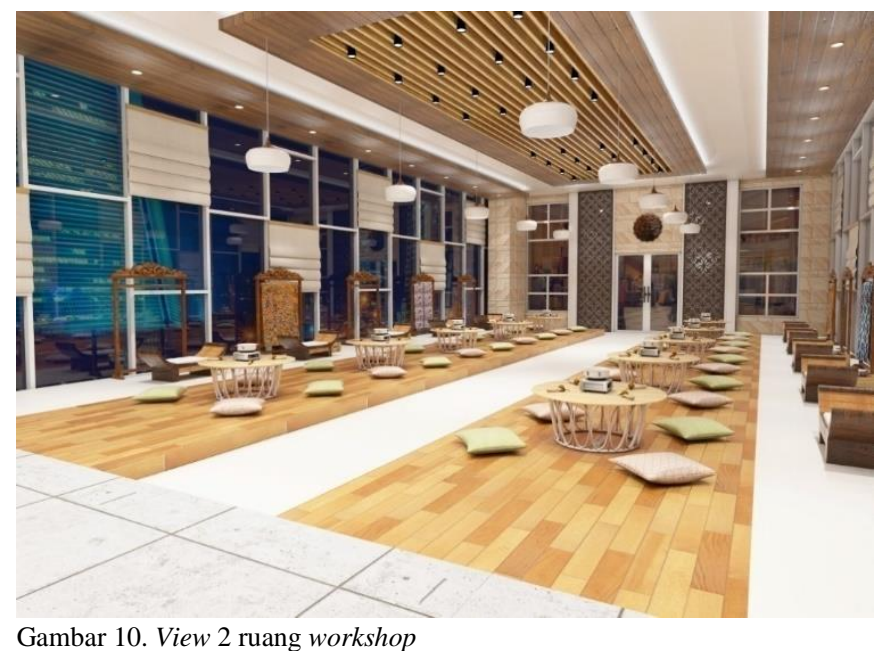

\section{Ruang Terpilih-Perpustakaan}

Pada gambaran visualisasi $3 \mathrm{~d}$ ruang perpustakaan nampak sekali terlihat berbeda dengan 2 ruang yang lain, kesan playful dan colorfull sangat dominan. Desain dan perencanaan ruang tersebut dilakukan, agar pengunjung yang melakukan aktifitas membaca buku didalamnya tidak merasa cepat bosan. Penggunaan warna yang cerah dan segar pada interior ruangan, terbukti bisa mempengaruhi psikologi penggunanya menjadi lebih bersemangat. Elemen gaya kontemporer dan Jawa Timur terlihat dari pemilihan furniture lemari baca, bench, meja dan bukaan yang lebar pada jendela, sedangkan elemen interior Jawa Timur diterapkan pada list plafon kayu dengan ukiran Majapahit dan perulangan penggunaan motif kawung pada penutup kusen di pintu geser, meja bundar rotan dan elemen estetis pajangan dinding barongan. 


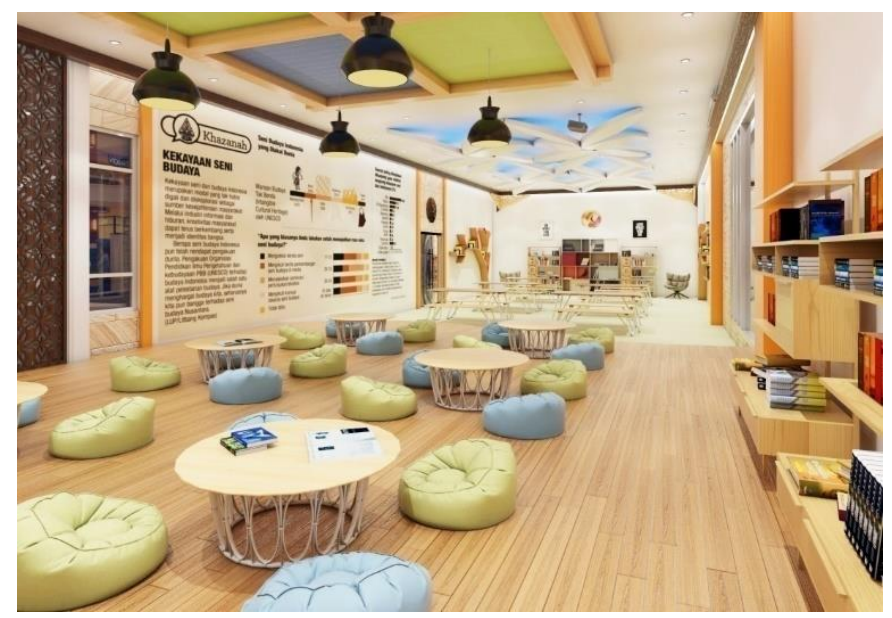

Gambar 11. View 1 perpustakaan

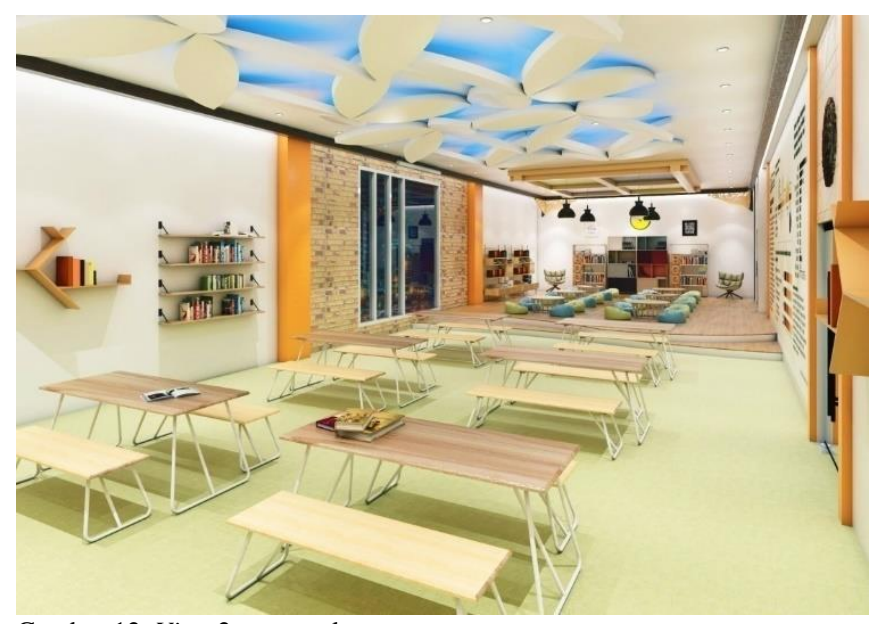

Gambar 12. View 2 perpustakaan

\section{KESIMPULAN}

Dalam pengembangan fasilitas galeri rumah batik Jawa Timur, pada tugas akhir ini. Penulis ingin menciptakan sebuah desain ruang yang memadukan antara kenyamanan pengguna, dengan kegiatan edukasi berupa workshop dan sarana belanja didalamnya. Dengan penyajian konsep desain berupa kontemporer dan ciri khas Jawa Timur, diharapkan pengunjung lebih antusias dalam mengikuti segala aktifitas pembelajaran dan transaksi komersil lain didalamnya, dengan tetap bisa merasakan suasana dan kesan etnik khas Jawa Timur, sehingga meninggalkan kesan unik tersendiri bagi pengunjung.

\section{DAFTAR PUSTAKA}

[1] Java Wisata IndonesiaTour and Organizer. (2013). Tentang Jawa Timur. [online]. Available : http://javawisataindonesia.wordpress.com/tentangjawa-timur/.

[2] Wardhana, Mahendra. Bahan Kuliah: Metodologi Riset Interior. Surabaya: Institut Teknologi Sepuluh Nopember. (2013)

[3] Aritonang, Liesbeth. 2015. Bahan Kuliah: Desain Interior. Medan: Institut Sains dan Teknologi Pardede. (2015) 